\title{
Wittgenstein sobre os fundamentos da linguagem e da significação
}

Wittgenstein on the fundations of language and meaning

\author{
MIRIAN DONAT ${ }^{27}$
}

Resumo: O artigo apresenta algumas considerações acerca dos fundamentos da linguagem e da significação no Wittgenstein tardio. Estas considerações têm como base algumas passagens das Investigações Filosóficas e do Da certeza, em especial a distinção realizada por Wittgenstein entre proposições empíricas e proposições gramaticais. Pretende-se mostrar que a linguagem e a significação têm como horizonte de justificação uma prática comum de uma determinada forma de vida, prática que se estabelece de acordo com regras compartilhadas que, quando explicitadas, tomam a forma de proposições gramaticais.

Palavras-chave: Wittgenstein. Linguagem. Significação. Forma de Vida.

Abstract: This paper presents some considerations about the foundations of language and meaning in the later Wittgenstein. These considerations are based on certain passages of the Philosophical Investigations and On certainty, especially the distinction made by Wittgenstein between empirical propositions and grammatical propositions. It is intended to show that language and meaning have as the horizon of justification a common practice of a certain form of life, a practice that is established according to shared rules that, when stated explicitly, take the form of grammatical propositions.

Keywords: Wittgenstein. Language. Significance. Life Form.

Nas Investigações Filosóficas, em meio à argumentação que tem

27 Professora Doutora do Departamento de Filosofia da UEL e exacadêmica bolsista do PET/Filosofia da UNIOESTE. 
Wittgenstein sobre os fundamentos da linguagem e da significação

como objetivo o esclarecimento dos conceitos de regras e seguir regras, Wittgenstein faz uma afirmação que se tornou bastante conhecida e comentada:

“Como posso seguir uma regra?" - Se isto não é uma pergunta pelas causas, é então uma pergunta pela justificação para o fato de que eu ajo segundo a regra assim.

Se esgotei as justificações, então atingi a rocha dura e minha pá entortou. Estou então inclinado a dizer: "é assim que eu ajo" (WITTGENSTEIN, 1996, § 217).

Partindo desta afirmação pretendemos, no que segue, apresentar algumas considerações acerca do entendimento de Wittgenstein sobre os fundamentos da linguagem e da significação. Pretendemos mostrar que a justificação à qual Wittgenstein se refere na passagem citada deve ser compreendida como um modo de agir que está na base de toda a linguagem e que, de acordo com isto, os fundamentos da linguagem e da significação aparecem como uma prática compartilhada de uma forma de vida. Revelar o que exatamente constitui esta prática compartilhada é que nos permitirá entender o modo peculiar com que Wittgenstein trata a questão, pois como ele mesmo afirma, "a fundamentação, a justificação da evidência tem um fim - mas o fim não é o fato de certas proposições se nos apresentarem como sendo verdadeiras, isto é, não se trata de uma espécie de ver de nossa parte; é o nosso atuar que está no fundo do jogo de linguagem" (WITTGENSTEIN, 2000, § 204).

Como se pode perceber desde já, a grande dificuldade de tratar da questão dos fundamentos da linguagem em Wittgenstein diz respeito a uma tensão entre a defesa de um fundamento para a linguagem e a significação, mas ao mesmo tempo suas recorrentes 
afirmações de que a fundamentação deve ter um fim e que este fim é um atuar, um agir. Esta tensão acontece tendo em vista que, tradicionalmente, a questão da fundamentação é considerada de uma perspectiva proposicional, em que um conjunto de proposições absolutamente verdadeiras poderiam ser tomadas como os fundamentos últimos para a verdade e para a própria possibilidade do conhecimento. Neste modelo, a verdade das proposições é fundamentada por meio de procedimentos lógico-dedutivos que levariam da certeza dos fundamentos para a verdade do conhecimento neles fundamentados, ou seja, a verdade do conhecimento estará condicionada à certeza de um conjunto de proposições fundamentais.

Para Wittgenstein a busca pelos fundamentos da linguagem e da significação tem a ver diretamente com a questão acerca da validade intersubjetiva da linguagem, ou, dito em outras palavras, das condições sob as quais podemos afirmar o sentido e a validade de nossas expressões linguísticas e que assim tornam possível e válido os diferentes e diversos jogos de linguagem, compreendidos como os contextos nos quais a linguagem e a comunicação efetivamente se realizam. Em Wittgenstein temos, portanto, a busca pelas condições de possibilidade da linguagem com sentido, condições estas que possibilitam o próprio desenvolvimento e funcionamento dos diferentes jogos de linguagem. É neste sentido que ele afirma, no parágrafo 90 das Investigações Filosóficas que:

É como se devêssemos desvendar os fenômenos: nossa investigação, no entanto, dirige-se não aos fenômenos, mas, como poderíamos dizer, às possibilidades dos fenômenos. Refletimos sobre o modo das asserções que fazemos sobre os fenômenos... Nossa consideração é, por isso, gramatical. E esta consideração traz luz para o nosso problema, afastando os mal- 
entendidos. Mal-entendidos que concernem ao uso das palavras; provocados, entre outras coisas, por certas analogias entre as formas de expressão em diferentes domínios da nossa linguagem.

A análise gramatical deverá revelar as condições de possibilidade dos jogos de linguagem, que podem ser compreendidas como os fundamentos dos mesmos, no sentido de que serão estas condições que determinarão o que faz e o que não faz sentido num jogo de linguagem, que mostram o que é o que não é um lance válido naquele jogo de linguagem. E uma das maiores contribuições dessa análise será a dissolução de muitos mal-entendidos, principalmente provocados por "certas analogias entre as formas de expressão em diferentes domínios da nossa linguagem”.

Por isso, a demonstração do que sejam estes condições passa, em nosso entendimento, pela distinção que Wittgenstein apenas sugere em algumas passagens de Investigações filosóficas e que desenvolve de forma mais decisiva em seu último conjunto de observações, o texto que foi publicado como Da certeza, a distinção entre proposições empíricas e proposições gramaticais. Nas Investigações esta distinção aparece, por exemplo, no parágrafo 251, em meio ao argumento da linguagem privada, em que afirma “Não posso me representar o contrário' naturalmente não significa aqui: minha força de representação não é suficiente. Nós nos defendemos com estas palavras contra aquilo que, por sua forma, simula uma proposição empírica, mas é na verdade uma frase gramatical”. Em nossa linguagem, muitas proposições que têm a forma de uma proposição empírica são, na verdade, frases gramaticais que, entretanto, muitas vezes não percebemos como tais, o que leva àquelas analogias citadas anteriormente. A investigação gramatical que Wittgenstein desenvolve no Da certeza tem como um de seus objetivos centrais exatamente 
DONAT, M.

esta distinção entre diferentes proposições, diferenças que não podem ser evidenciadas pela simples forma delas, mas sim pelo uso que delas é feito na linguagem.

Como se sabe, em Da certeza o objetivo principal de Wittgenstein era mostrar o equívoco da afirmação de Moore de que "sabe com certeza" que certas proposições, por ele consideradas truísmos, tais como "Existem objetos físicos", "A terra existe a muitos anos", "Eu sei que aqui está minha mão", são verdadeiras. Moore pretendia que estas proposições do senso comum pudessem provar a existência de coisas fora de nós, como a terra, outros corpos humanos, as nossas mãos, refutando com isso as pretensões do cético ao estabelecer um conhecimento com certeza.

Considerando todas como proposições empíricas, Moore entendeu que algumas delas eram imunes à dúvida e que serviriam como as proposições fundamentais das quais todas as outras podiam ter sua verdade deduzida. Assim, a partir destas certezas do senso comum poder-se-ia estabelecer um fundamento seguro para $o$ conhecimento. O reconhecimento da impossibilidade de duvidar de uma série de proposições como estas permite deduzir a verdade de certas teses, tais como a tese da existência de objetos físicos. Teríamos assim, segundo Moore, finalmente encontrado uma base segura sobre a qual estabelecer o conhecimento.

No Da certeza Wittgenstein se empenha detidamente a criticar a postura de Moore com relação a estas "verdades fundamentais". Wittgenstein reconhece o valor do empreendimento de Moore e que Moore teria tocado num ponto fundamental, qual seja, de que há certas proposições na nossa linguagem das quais não faz nenhum sentido duvidar. Entretanto, a falta de sentido da dúvida em relação a 
elas não se explica pelas conclusões a que chegou Moore e todo o $D a$ certeza será dedicado a demonstrar o modo correto de compreender a impossibilidade da dúvida em relação a estas proposições.

Segundo Wittgenstein, Moore estava correto em tentar confrontar o cético e defender a verdade dos 'truísmos' do sendo comum; a sua intuição é correta, entretanto ele não teria percebido o verdadeiro alcance dessa intuição e teria utilizado uma estratégia ineficaz para atingir seu objetivo. $O$ equívoco de Moore foi não ter percebido que muitas das nossas proposições têm a mesma forma, a forma de uma proposição empírica, entretanto esta forma comum esconde os diferentes papéis que as proposições ocupam na nossa linguagem. Moore não teria se dado conta da diferença categorial entre os tipos de proposição que expressam conhecimento e aquelas que expressam certeza:

'saber' e 'certeza' pertencem a diferentes categorias. Não são dois 'estados mentais' como, por exemplo, 'supor' e 'estar seguro'. Aquilo que nos interessa agora não é estar seguro mas saber. Isto é, interessa-nos o fato de que não pode existir qualquer dúvida acerca de certas proposições empíricas, se é de fato possível formular juízos. Ou ainda: estou inclinado a crer que nem tudo que tem a forma de uma proposição empírica o é (WITTGENSTEIN, 2000, § 308).

A análise de Wittgenstein incide sobre o sentido daquele tipo específico de proposições, pois, diferentemente de Moore, este sentido não pode ser o de expressar qualquer tipo de saber, no caso, um saber imune a todo tipo de dúvida. Wittgenstein apenas aceita a conclusão de Moore de que tais proposições são imunes à dúvida, mas isto não significa que expressem um conhecimento imune à dúvida. E sua análise visa demonstrar justamente que sempre que uma proposição 
DONAT, M.

expressa um conhecimento ela tem que já ser passível de dúvida, pois do jogo de linguagem que envolve conhecimento faz parte a possibilidade de se duvidar de tudo aquilo que alguém diz saber.

Para Wittgenstein apenas das proposições empíricas é que podemos afirmar que são verdadeiras ou falsas, ou seja, que são bipolares. E a verdade destas proposições se estabelece a partir de determinadas provas ou evidências que servem como justificativa para a sua verdade. Um exemplo de tais proposições seria "Eu sei que a terra existe a 4,6 bilhões de anos" ou "Eu duvido que a terra existe a 4,6 bilhões de anos", onde as expressões "eu sei" e "eu duvido" estão sendo usadas corretamente. E elas são usadas corretamente porque se forem exigidas justificativas elas poderão ser dadas, poderão ser apresentadas provas para tais afirmações, pois "não bastaria assegurar a alguém que eu sei o que acontece num certo lugar - sem lhe dar fundamentos que o convençam de que eu tenho possibilidade de saber" (WITTGENSTEIN, 200o, § 438). E isto significa que a expressão "eu sei" usada sem esses fundamentos não tem um papel neste jogo de linguagem.

Um aspecto importante que Wittgenstein acentua é que estes fundamentos são sempre publicamente acessíveis, o que significa que o conhecimento não é algo que é fruto de uma experiência pessoal, nem um fenômeno, estado ou processo mental e nem, por isso mesmo, algo que possa ser descoberto por introspecção: "o fato de uma proposição poder revelar-se falsa depende, em última instância, daquilo que eu considerar como determinantes dessa proposição" (WITTGENSTEIN, 2000, § 5) e isto que é considerado determinante são condições expressas como regras de um jogo de linguagem, regras estas que servem como critérios que permitem afirmar o que é 
verdadeiro e o que é falso neste jogo de linguagem, no mesmo sentido em que determinam o que faz e o que não faz sentido: "aquilo que conta como prova adequada de uma afirmação é do domínio da lógica. Pertence à descrição do jogo de linguagem" (WITTGENSTEIN, 200o, § 82).

Os critérios de verdade funcionam como regras para o uso correto deste tipo de proposições, ou seja, para que possamos fazer afirmações e pretender que sejam verdadeiras temos que ser capazes de apresentar as condições sob as quais aquilo que é afirmado é verdadeiro, apresentando provas ou evidências que possam justificar aquilo que é afirmado. Estes são movimentos possíveis nesse jogo de linguagem: que alguém duvide do que é afirmado, que o outro apresente as provas para o que afirma, que a dúvida possa ser sanada e que se possa concordar sobre a verdade da afirmação. A dúvida e a verdade são possibilidades de um jogo de linguagem enquanto lances possíveis deste jogo de linguagem, são movimentos que os falantes realizam dentro do jogo de linguagem.

Entretanto, este não é o caso dos "truísmos" de Moore. Aquelas proposições consideradas por Moore como absolutamente verdadeiras não são, da perspectiva de Wittgenstein, proposições empíricas no sentido acima exposto. Tais proposições, apesar de ter a forma de uma proposição empírica, não o são pelo fato de que não são proposições bipolares, elas não trazem em si a possibilidade de ser verdadeiras ou falsas. Wittgenstein concorda com Moore que tais proposições são imunes à dúvida, mas é isto justamente que mostra que não expressam conhecimento, ou seja, não se trata de proposições empíricas. Se fossem consideradas como proposições empíricas deveriam ser sem sentido, pois não sendo bipolares não dizem nada. 
Mas Wittgenstein observa que tais proposições têm um uso em nossa linguagem e desvendar qual seja este uso é o que permitirá demonstrar qual é o seu sentido. O principal objetivo de Wittgenstein com esta distinção será estabelecer a distinção entre saber e certeza, mas tem também o importante papel de demonstrar quais sejam os fundamentos da linguagem e da significação, nosso objetivo nesse momento.

Como vimos, para Wittgenstein a dúvida só tem sentido onde existe a possibilidade de saná-la, ou seja, só faz sentido duvidar de uma proposição quando temos a possibilidade de resolver essa dúvida, pois a dúvida deve ter um fim; duvidar é uma prática de um jogo de linguagem que pressupõe certeza, o que significa que uma dúvida sem fim não faz sentido e isto, por sua vez, significa que para que possa haver dúvida em relação sobre se uma proposição é verdadeira ou falsa, é preciso que possamos chegar a um fim no processo de buscar as justificativas ou provas para afirmar que nossa proposição é verdadeira.

Aquelas proposições apresentadas por Moore como sendo absolutamente verdadeiras não são proposições das quais podemos duvidar, como ele mesmo afirma, e Wittgenstein pensa da mesma forma: "sabemos, com a mesma certeza com que acreditamos em qualquer proposição matemática, como se pronunciam as letras A e B, como se chama a cor do sangue humano, que outros seres humanos têm sangue e chamam isso de sangue" (WITTGENSTEIN, 2000, § 340).

Segundo Wittgenstein as proposições gramaticais devem ser consideradas como os fundamentos das nossas práticas lingüísticas, o que significa, entre outras possibilidades, que devem ser tomadas como regras para o funcionamento dos nossos jogos de linguagem: 
Isto é, as perguntas que formulamos e as nossas dúvidas dependem do fato de certas proposições estarem isentas de dúvida serem como que dobradiças em volta das quais as dúvidas giram.

Isto é, pertence à lógica das nossas investigações científicas que certas coisas de fato não sejam postas em dúvida (WITTGENSTEIN, 200o, § 341-342)

As proposições de Moore são aceitas por nós como verdadeiras, sem dúvida. Não aceitar isto implica em termos de proceder a uma mudança radical em nosso sistema de referência, como um todo e é como se fosse uma decisão inconsciente tomá-las como verdadeiras, esse é o significado de estarem além ou aquém de toda justificação: "dizer do homem, no sentido de Moore, que ele sabe alguma coisa, que o que ele diz é, portanto, incondicionalmente verdade, parece-me errado. É verdade só na medida em que é uma base inamovível nos seus jogos de linguagem" (WITTGENSTEIN, 2.00o, § 403). Por isso que não podemos provar sua verdade, aceitá-las como tal faz parte da "mitologia" do modo como vemos as coisas. A certeza conferida a estas proposições não implica na possibilidade de serem verdadeiras ou falsas.

Falar em fundamentos em Wittgenstein significa uma consideração dos fundamentos não nos mesmos termos daquilo que é fundamentado, é distinguir justamente aquilo que precisa de fundamentação daquilo que o fundamenta e que não pode ser fundamentado. É desta perspectiva que devem ser compreendidas as regras de um jogo de linguagem. Estas regras são as condições que permitem o funcionamento de um determinado jogo de linguagem; entretanto, como condições que são não podem ser lances dentro do próprio jogo de linguagem. "Existem objetos físicos" é uma regra que permite que possamos falar de objetos, que possamos descrevê-los, 
apontá-los, e assim por diante:

"A é um objeto físico" é uma indicação que damos a alguém que não percebe ainda o que significa " $A$ " ou o que significa "objeto físico". Assim, é uma indicação sobre o uso de palavras, e "objeto físico" é um conceito lógico (tal como cor, quantidade...) E é por isso que não pode ser formulada uma proposição como "Há objetos físicos".

Contudo, encontramos frequentemente tentativas mal-sucedidas desse gênero (WITTGENSTEIN, 200o, §36).

Wittgenstein expressa essa assimetria entre o que é fundamentado e o seu fundamento também do seguinte modo: "Se a verdade é o que é fundamentado, então o fundamento não é verdadeiro nem falso". Não faz sentido dizer que o fundamento é verdadeiro (ou falso); ao menos, não no sentido que faz dizer que aquilo que é fundamentado é verdadeiro. Se usamos a nossa linguagem, aceitamos o fundamento como fundamento - sem prova. Ele é um dado. Se admitirmos a possibilidade de provar que ele é um fundamento, estaremos tentando nos colocar fora da linguagem, considerando-a como um todo, juntamente com o seu fundamento, e tentando determinar de um padrão exterior se ela é correta, verdadeira. Mas o fazemos usando a palavra 'verdadeiro', tentando jogar o jogo de linguagem no qual dizemos que as proposições fundamentadas são verdadeiras; ou seja, fazemo-lo tentando efetuar um lance dentro de um jogo de linguagem. Podemos pedir razões apenas dentro da linguagem e não podemos, portanto, pedir razões para a linguagem: "não posso sair fora da linguagem com a linguagem".

Essa reflexão pode parecer paradoxal àquele que concebe o 
Wittgenstein sobre os fundamentos da linguagem e da significação

fundamento como um conjunto de proposições. Se forem proposições, como pode a questão sobre sua verdade ou falsidade não ter importância. Esse caráter paradoxal, no entanto, pode desaparecer se reconhecermos que, na verdade, aquilo que Wittgenstein entende serem os fundamentos da linguagem são modos de agir incorporados numa forma de vida.

O acordo nas formas de vida é logicamente anterior ao acordo em opiniões. Acordo na forma de vida é nosso acordo em uma imagem compartilhada de mundo. E essa imagem de mundo forma o pano de fundo sob o qual distinguimos entre verdade e falsidade. $\mathrm{Ou}$, dizendo de outro modo, o acordo na forma de vida é o acordo em um conjunto de proposições gramaticais que, entre outras coisas, descreve o que conta como aquilo que fornece os fundamentos para a verdade das declarações dentro de nossos diferentes jogos de linguagem. Assim, o acordo na forma de vida é o que fundamenta nossa capacidade de comunicação, de argumentação e investigação. Ele fornece a estrutura dentro da qual o acordo em opiniões pode ou não ter lugar. A forma de vida dentro da qual as declarações de uma comunidade contam como verdadeiras ou falsas não pode ela mesma ser colocada em questão, porque o conjunto de proposições gramaticais que são aceitas como verdadeiras forma a base sobre a qual fazemos julgamentos. Não se pode colocar em questão a totalidade das sentenças que numa forma de vida são consideradas certezas, de uma só vez, se queremos continuar julgando. É a estrutura dentro da qual os seres humanos formam e expressam crenças e fazem afirmações. Além disso, é a estrutura dentro da qual elaboram métodos para testar suas crenças e asserções.

Portanto, o que está na base dos jogos de linguagem não é algo 
que possa ser justificado ou não: "é algo animal" (WITTGENSTEIN, 200o, § 359): a base dos jogos de linguagem é uma forma de agir, o agir típico deste animal que é o homem, com todas as suas práticas, atividades.

Mas a fundamentação, a justificação da evidência tem um fim mas o fim não é o fato de certas proposições se nos apresentarem como sendo verdadeiras, isto é, não se trata de uma espécie de ver da nossa parte; é o nosso atuar que está no fundo do jogo de linguagem.

Se o verdadeiro é o que é fundamentado, então o fundamento não é verdadeiro nem falso (WITTGENSTEIN, 2000, § 204-205).

As nossas certezas formam um "quadro de referências" (WITTGENSTEIN, 2000, § 83) de acordo com o qual podemos jogar nossos diferentes e múltiplos jogos de linguagem, tais como "comandar, perguntar, contar, tagarelar". Nossa confiança nesse quadro de referências é devido as nossas práticas comuns e regulares, próprias de nossa forma de vida e é para nós totalmente natural. Faz parte da nossa natureza, assim como "andar, comer, beber, jogar" (WITTGENSTEIN, 1996, § 25) E aquilo que faz da nossa natureza não precisa de outro tipo de justificação do que o próprio fato de que é assim que agimos, todas estas práticas linguísticas são ações próprias deste ser que é o ser humano, fazem parte de sua história natural. E sem deixar de notar que, para Wittgenstein, a "história natural" do homem não se reduz a suas características biológicas, mas que faz parte de sua "natureza" características culturais, dentre as quais a própria linguagem, nas suas diferentes manifestações como diferentes jogos de linguagem.

Portanto, podemos afirmar que o cético pode lançar desafios em 
Wittgenstein sobre os fundamentos da linguagem e da significação

relação à verdade de proposições empíricas, mas não pode colocar em questão a própria base que fundamenta esta possibilidade. Para que se possa questionar a verdade de certas proposições é preciso que se aceite como imunes à dúvida certo conjunto de outras proposições que são a condição da própria dúvida. As justificações têm um fim neste exato sentido: não podemos duvidar de tudo o tempo todo, a dúvida só faz sentido lá onde podemos dirimi-la e esta possibilidade depende de se tomar algo como isento de dúvida. Este esquema não pode ser fundamentado, ele é aceito como um todo:

Mas eu não obtive a minha imagem de mundo por me ter convencido da sua justeza, nem a mantenho porque me convenci da sua justeza. Pelo contrário, é o quadro de referências herdado que me faz distinguir o verdadeiro do falso.

As proposições que descrevem esta imagem do mundo poderiam pertencer a uma espécie de mitologia. E o seu papel é semelhante ao das regras de um jogo. E o jogo pode ser aprendido puramente pela prática, sem aprender quaisquer regras explícitas (WITTGENSTEIN, 2000, § 94-95).

\section{Referências bibliográficas}

COLIVA, A. Moore and Wittgenstein. New York: Palgrave, 2010.

ELLENBOGEN, S. Wittgenstein's account of truth. Estados Unidos: SUNY Press, 2003.

MOYAL-SHARROCK, D. Understanding Wittgenstein's On certainty. New York: Palgrave, 2004.

WITTGENSTEIN, L. Investigações filosóficas. São Paulo: Nova Cultural, 1996.

WITTGENSTEIN, L. Da certeza. Lisboa: Edições 70, 2000. 